\title{
RÁPIDO MOVIMIENTO DE PLANTAS EXÓTICAS EN LA ZONA CENTRAL DE ChILE. UNA RECONSTRUCCIÓN A TRAVÉS DE EVIDENCIA HISTÓRICA Y PALINOLÓGICA
}

\author{
PATRICIA VARGAS ${ }^{1}$, FERNANDO TORREJÓN², ANÍBAL PAUCHARDD ${ }^{3,4}$ y ROBERTO URRUTIA²
}

\begin{abstract}
Summary: Fast movement of alien species in the central region of Chile. Reconstruction through history and palynological evidence.To understand the dynamics of plant communities that currently comprise central Chile, a pollen-sedimentary analysis was performed that differentiated between native and exotic taxa. This was complemented with a historical reconstruction of the past 500 years of the Itata valley, Bio-Bio Region. With this, three historical periods were established: Pre-hispanic Situation, the valley is described as a plain provided with xeromorphic vegetation, poor in species; Agricultural and Livestock Boom period, the first exotic plants emerged: Poaceae> 40um, Rumex, Rutaceae, Prunus, shamrocks and thistles, which acclimatized and expanded rapidly, boosted further by war conflicts and socio-cultural movements of the XVII-XIX centuries; Forestry Period, the following exotic species were registered: Alnus, Acacia, Eucalyptus, Cupressus and Pinus, introduced with the objective of halting soil erosion and meet the growing demand in wood. In only 250 years (1600-1850), the number of exotic species may have equaled native species. However, these may have adapted to less favorable soils, not greatly affecting the native trees. Stands out the pine, its introduction in the region may have occurred in $\sim 1850$, taking only 50 years to dominate the natural landscape of the basin
\end{abstract}

Key words: introduction, plants, pollen, comparison, historical data.

Resumen: Para comprender la dinámica de las comunidades vegetales que conforman actualmente a la zona central de Chile, se realizó un análisis polínico-sedimentario que diferenció entre taxones nativos y exóticos. Este fue complementado con una reconstrucción histórica de los últimos 500 años del valle Itata, Región del Bio-Bio. Con lo anterior, se establecieron tres periodos históricos: Situación Prehispánica, se describe al valle como un llano provisto de vegetación xeromórfica, pobre en especies; Periodo de Auge Agrícola-ganadero, caracterizado por la aparición de las primeras plantas exóticas: Poaceae $>40$ um, Rumex, Rutaceae, Prunus, tréboles y cardos, las cuales se aclimataron y expandieron rápidamente, favorecidas aún más, por los conflictos bélicos y movimientos socioculturales de los siglos XVII-XIX; Periodo Forestal, dónde se registraron especies de rápido crecimiento como: Alnus, Acacia, Eucalyptus, Cupressus y Pinus, introducidas con los objetivos de detener la erosión de los suelos y de satisfacer la creciente demanda en madera. En sólo 250 años (1600-1850) la cantidad de especies exóticas habría igualado a las especies nativas. No obstante, estas se habrían adaptado a suelos menos favorecidos, no afectando mayormente a los árboles nativos. Entre estas plantas destaca el pino, su introducción en la región habría ocurrido en 1850, tardando sólo 50 años en dominar el paisaje natural de la cuenca.

Palabras clave: introducción, plantas, polen, comparación, data histórica.

${ }^{1}$ Departamento de Prevención de Riesgos y Medio Ambiente, Universidad Tecnológica Metropolitana (UTEM), Santiago, Chile,pvargas@utem.cl.

2 Unidad de Sistemas Acuáticos, Centro de Ciencias Ambientales EULA-Chile, Universidad de Concepción, Concepción, Chile, ftorrejo@udec.cl; rurrutia@udec.cl.

${ }^{3}$ Laboratorio de Invasiones Biológicas (LIB), Facultad de Ciencias Forestales, Universidad de Concepción, Concepción, Chile.

${ }^{4}$ Instituto de Ecología y Biodiversidad (IEB), Facultad de Ciencias, Universidad de Chile, Casilla 653, Santiago, Chile, pauchard@udec.cl 


\section{INTRODUCCIÓN}

La modificación de las floras regionales, como resultado de la introducción de especies y el incremento de las perturbaciones asociadas a las actividades antrópicas, es una de los principales causantes de la pérdida de biodiversidad (Sala et al., 2000). Esta problemática es particularmente relevante en áreas con una larga historia de asentamientos humanos, como lo son los ecosistemas mediterráneos (Hernández et al., 2016). La vegetación natural de las zonas mediterráneas ha sido modificada profundamente generando cambios en la dinámica, estructura y funcionamiento de estos sistemas. Se estima que las zonas mediterráneas del planeta representan sólo 5\% de la superficie de la tierra, no obstante, soporta el $20 \%$ de las especies de plantas de todo el mundo (Cowling et al., 1996), siendo consideradas uno de los ecosistemas más vulnerables a los cambios del paisaje natural.

El proceso antrópico de transformación de la vegetación y del paisaje natural ha sido diferente en las distintas regiones del mundo. En Chile, comenzó con la domesticación de las especies de plantas y animales para la agricultura y se expandió aún más con el proceso de conquista o llegada de los colonizadores españoles a nuevas tierras (Torrejón \& Cisterna, 2002). Se estima, que a la llegada de los españoles, había una población indígena de un millón de personas situadas al sur de Santiago. Estos asentamientos se distribuían de forma dispersa, en lugares previamente despejados de los bosques, dónde se desarrollaban diversas actividades económicas capaces de sostener a la población (Camus, 2006). Sin embargo, con la llegada de los conquistadores, el uso extensivo del territorio se acentúo drásticamente, iniciándose el proceso de transformación del paisaje natural más importante (Camus, 2006; Otero, 2006).

Los españoles llegaron al país durante el s. XVI, trayendo consigo nuevas especies de animales y vegetales, además de otras técnicas de cultivo y tecnologías, que diferían con las prácticas tradicionales de las etnias nativas (Torrejón \& Cisterna, 2002). Las nuevas especies fueron rápidamente asimiladas por los indígenas expandiéndose y aclimatándose con gran éxito en toda la zona mediterránea del país, pasando a formar parte del paisaje regional (Figueroa et al., 2004; Pauchard et al., 2011; Torrejón \& Cisterna, 2002).
La presencia de los conquistadores generó una respuesta inmediata de los indígenas, de los cuales destacan los mapuches, quienes opusieron una larga resistencia, defendiendo fundamentalmente el territorio que se extiende entre las actuales Región del Bio-Bio $\left(36^{\circ} \mathrm{S}\right)$ y Los Lagos $\left(41^{\circ} \mathrm{S}\right)$. Este proceso bélico favoreció la introducción y propagación de nuevas especies a nuevos territorios. Posteriormente, a partir de la Independencia de Chile (XIX), comenzó un nuevo proceso de desarrollo económico y cultural que llevó a la introducción de muchas especies de plantas para fines agrícolas, ganaderos y medicinales (Arroyo et al., 2000; Marticorena \& Rodríguez, 1995). La introducción de especies vegetales persistió durante todo el $\mathrm{s}$. XIX e inicios del s. XX, sin embargo, hacia fines de este último periodo se centró en las plantas con fines forestales como Pinus pinaster, Eucalyptus globulus, Acacia melanoxylon, entre otras (Aguayo et al., 2009; Camus, 2006). Posteriormente, a consecuencia del desarrollo exitoso de las especies forestales, se dio comienzo a los cultivos silvícolas intensivos y extensivos, los cuales son actualmente los de mayor importancia económica para la Región del Bio-Bio y el país (Frêne \& Núñez, 2010).

La Región del Bio-Bio $\left(36^{\circ} \mathrm{S}\right)$ presenta la mayor superficie de plantaciones forestales y es la segunda, después de la Región de la Araucanía, con mayor superficie de suelos agrícolas (INE, 2007). Esto ligado a una alta densidad poblacional (INE, 2013), asociada a mayores niveles de perturbación antrópica y a una larga historia de asentamientos humanos (Arroyo et al., 2000), conlleva a que la zona sea propicia para el desarrollo de taxa exóticos (Figueroa et al., 2011; Pauchard et al., 2006). La zona mediterránea de Chile central $\left(31-38^{\circ} \mathrm{S}\right)$ contiene una riqueza florística de 2395 especies nativas, de las cuales el $50 \%$ son endémicas del país (Arroyo \& Cavieres, 1997). No obstante, en Chile habrían 743 especies exóticas (Pauchard et al., 2011), de las cuales 381 se encontrarían en la Región del Bio-Bio (Jiménez et al., 2008), siendo la con mayor diversidad de especies introducidas del país. Actualmente la Región presenta una riqueza tanto de especies nativas como exóticas. Sin embargo, los procesos y/o mecanismos que determinan y caracterizan la diversidad de estas comunidades y su distribución, son aspectos poco conocidos en Chile central (Figueroa et al., 2004). Particularmente, no existe la información necesaria 


\section{P. Vargas et al. - Rápido movimiento de plantas exóticas en Chile Central}

que permita aclarar cuál ha sido la interacción a través del tiempo entre los taxa nativos y exóticos.

Los registros polínicos sedimentarios evidencian los cambios que ha tenido la vegetación a través del tiempo, producto de la interacción de los factores ambientales y antrópicos (Boyd \& Hall, 1998; Foster et al., 1990). Mediante estos se puede establecer una cronosecuencia temporal desde el establecimiento de las especies introducidas, y evaluar los cambios que se han generado en la vegetación, comparando los periodos de pre y post introducción (Hobbie et al., 2003). Si bien, los estudios paleolimnológicos son ampliamente utilizados para inferir cambios en la biodiversidad (Odgaard, 2013), estos presentan varias fuentes de incertitud, asociadas principalmente a la taxonomía y a la escala espacial (Lisitsyna et al., 2011; NietoLugilde et al., 2015). En términos taxonómicos a menudo es imposible diferenciar especies de un mismo género (o en algunos casos familias; e.g. Poaceae) debido a la similitud en la morfología polínica de los taxones relacionados. Así mismo, establecer el dominio espacial que representa el registro polínico, es sumamente complejo ya que, depende de la cantidad de producción polínica, la capacidad de transporte del grano, la forma de polinización y la preservación (Lisitsyna et al., 2011; Nieto-Lugilde et al., 2015; Odgaard, 2013).

La exactitud de la interpretación, al momento de evaluar los registros sedimentarios, puede ser mejorada con datos históricos locales y/o regionales, los cuales pueden ayudar a identificar procesos $\mathrm{u}$ eventos difíciles de interpretar solamente con datos polínicos (Szabó, 2010). Sin embargo, los datos históricos precisos sobre introducción de especies son raros, sobre todo para especies exóticas que no se han establecido. Como consecuencia de ello, existen muy pocos estudios de registros polínicos de especies exóticas que sean respaldados por registros históricos. Hasta la fecha no hay ninguna investigación de este tipo en Chile, pese a que se ha demostrado que el momento de arribo de estas especies es de gran relevancia para entender su actual dispersión en el país (Figueroa et al., 2004). Por este motivo, es de suma importancia identificar: (i) cuando comenzaron a registrarse las diferentes plantas exóticas en la región (ii) cuales fueron estas especies (iii) y cuáles fueron los factores históricos y/o ambientales que han determinado a la vegetación actual.
El objetivo de este trabajo es responder los interrogantes planteados a través de un análisis histórico y palinológico sedimentario que permitirá reconstruir la historia de la vegetación de los últimos 500 años de la cuenca de la Laguna Avendaño, Región del Bio-Bio. Esta área fue seleccionada por situarse dentro de una zona que presenta larga data histórica (XVI-XIX), además de haber manifestado importantes transformaciones en el paisaje natural, debido a los diversos cambios en el uso de suelo generados desde la llegada de los españoles hasta la actualidad.

\section{Materiales y Métodos}

\section{Área de estudio}

La Laguna Avendaño (36 $45^{\prime} 144^{\prime}$ 'S $\left.72^{\circ} 26^{\prime} 56^{\prime \prime} \mathrm{O}\right)$ está situada a $55 \mathrm{~km}$ al noreste de la ciudad de Concepción y a $35 \mathrm{~km}$ al suroeste de la ciudad de Chillán. La altura promedio de la cuenca es de 65 m s.n.m, la superficie del lago es de $2 \mathrm{~km}^{2}$ y su cuenca de drenaje abarca 11 $\mathrm{km}^{2}$. Se sitúa en la Provincia de Nuble, formando parte de la cuenca del río Itata que se ubica en la parte sur del valle central de Chile (Fig. 1). La vegetación de esta cuenca se caracteriza por un bosque esclerófilo psamófilo mediterráneo interior (Gajardo, 1994). El dosel superior está dominado por Quillaja saponaria y Lithrea caustica, con presencia importante de Fabiana imbricata en el estrato arbustivo. Este bosque se desarrolla sobre condiciones de sustrato arenoso con escasa capacidad de retención, produciendo condiciones de déficit hídrico y una fisionomía vegetal más xeromórfica. En las zonas más húmedas, cercanas al litoral del lago o a los cursos de agua, se puede encontrar Myrceugenia exsucca, Drimys winteri, Blepharocalyx cruckshanksii, Pluchea absinthioides, y Baccharis pingraea (Gajardo, 1994; Luebert \& Pliscoff, 2006). Las zonas más altas de la cuenca presentan un bosque laurifolio valdiviano, donde destaca la presencia de Aextoxicon punctatum, Eucryphia cordifolia, Gevuina avellana, Luma apiculata, Lurzuriaga radicans, y Mirceugenia planipes, entre otras (Luebert \& Pliscoff, 2006).

La cuenca lacustre en estudio presenta actualmente múltiples usos, tales como: residencial, recreacional, agrícola, ganadero, silvícola e 
Bol. Soc. Argent. Bot. 52 (1) 2017

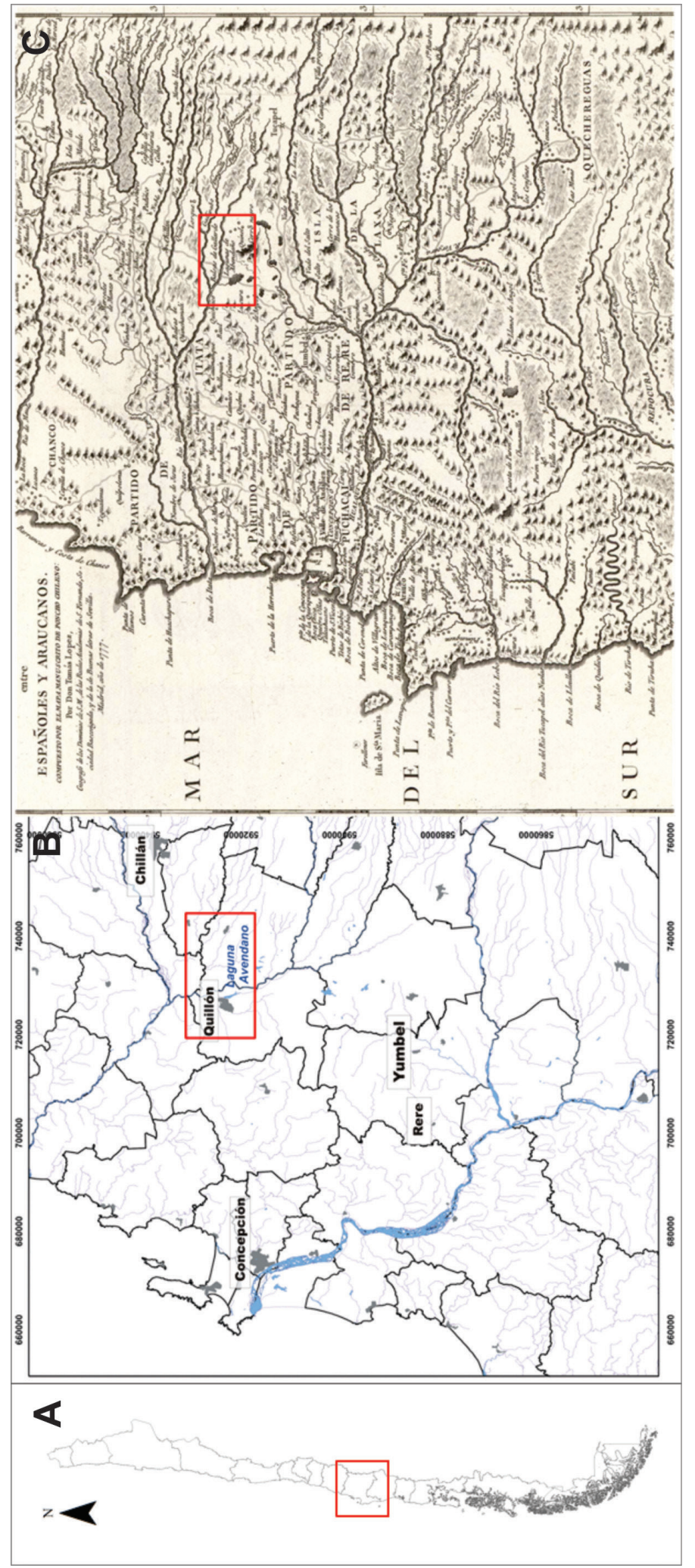

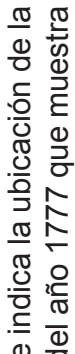

i $\frac{0}{\overline{1}}$

응 은 능

응 웅ㅇㅇㅇ

을 질

롱 을

응 응

뜐 :든 은

헝

ฮั क

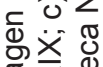

要这

수을

은 응

으 음은 은

क क ब

힝 으 흠

으 흔 뭉

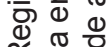

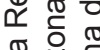

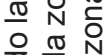

든 즌

중 흠

क

ब) त $\frac{\overline{1}}{2}$

U $\frac{0}{\omega} \frac{\pi}{0}$

응 흥

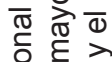

웡 웅

전

需 $\frac{0}{0} \frac{0}{2}$

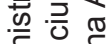

ह 응

드 은 뜨

:은 $\frac{2}{0} \frac{\pi}{0} \frac{\pi}{0}$

ㄷำ

응

․․

후 웜 


\section{P. Vargas et al. - Rápido movimiento de plantas exóticas en Chile Central}

industrial. Estas actividades han ejercido una fuerte presión sobre el paisaje natural, siendo el rubro silvícola el más desarrollado, asociado principalmente a la industria de celulosa, la que propicia en la Región las plantaciones de especies arbóreas de rápido crecimiento, siendo Pinus radiata la más abundante. El bosque nativo se encuentra actualmente muy reducido y fragmentado, como consecuencia del rápido desarrollo urbano e industrial, actividades que se han intensificado con fuerza en los últimos 30 años (Aguayo et al., 2009).

El clima de la zona central de Chile se caracteriza por ser Mediterráneo de estación seca prolongada, con lluvias de invierno y un verano carente de precipitaciones (Luebert \& Pliscoff, 2006; Miller, 1976). El promedio anual de las precipitaciones en la ciudad de Chillán es de $982 \mathrm{~mm}$ y las temperaturas fluctúan drásticamente entre las estaciones del año, pudiendo alcanzar un mínimo de $-2^{\circ} \mathrm{C}$ en invierno y un máximo de $35^{\circ} \mathrm{C}$ en verano (Dirección Meteorológica de Chile, 2011).

\section{Análisis físicos y geocronológicos}

El núcleo sedimentario se tomó en el invierno del año 2010. Para determinar la profundidad máxima del lago y establecer el punto de muestreo se utilizó una ecosonda Garmin modelo 178C. La columna de sedimento se extrajo con un muestreador de gravedad (gravity corer) marca UWITEC y un tubo de plexiglass de $6 \mathrm{~cm}$ de diámetro. Al núcleo sedimentario se le realizó una descripción del sedimento, mediante la carta de colores y la medición continua de la susceptibilidad magnética, utilizando el sensor Bartington MS2.

La edad de la columna sedimentaria fue determinada a través de la medición de los isótopos ${ }^{210} \mathrm{~Pb},{ }^{137} \mathrm{Cs}$ y ${ }^{14} \mathrm{C}$. Para el caso del ${ }^{210} \mathrm{~Pb}$ la metodología consideró la aplicación tanto del modelo CRS (Constant Rate Supply) como CIC (Constant Inicial Concentration) propuestos por Appleby \& Oldfield (1978). Mientras que las edades radiocarbónicas fueron obtenidas a partir de muestras de sedimento, las que fueron calibradas con el programa OxCal 4.1, usando la curva de calibración SHCa104 (McCormac et al., 2004).

\section{Análisis de polen}

Para el análisis de polen de los últimos 500 años se examinó hasta la profundidad de 65 centímetros. Además, se estableció una línea de base entre los centímetros 114 y $122(970$ - 860 AD) para registrar la vegetación previa a la llegada de los españoles a la zona. Las muestras sedimentarias fueron extraídas cada $2 \mathrm{~cm}$ y de cada fracción se tomó $2 \mathrm{ml}$ de sedimento húmedo $(\sim 0,4$ gr de sedimento seco). Posteriormente se procedió al tratamiento químico siguiendo la metodología de Erdtman (1960). Durante este proceso se agregaron microesferas para calcular las concentraciones de los diferentes taxones. El análisis se realizó con microscopio fotónico a 1000X de magnificación y para la identificación de los grupos polínicos se utilizó la bibliografía de referencia de Heusser (1971) y la base de datos de paldat (www.paldat.org). Durante el conteo de polen, se diferenció entre taxa nativos y exóticos. Cabe mencionar que la resolución a nivel de especie es muy difícil de alcanzar en algunos taxones debido a la similitud morfológica de los granos de polen. Por esto el perfil polínico fue más simplificado agrupando diferentes especies en géneros o familias (Lisitsyna et al., 2011; Nieto-Lugilde et al., 2015). Por lo tanto, si se comparan los taxones registrados en el perfil polínico con los identificados en la bibliografía analizada se puede señalar que: Plantago estaría compuesto por las especies exóticas $P$. major y $P$. lanceolata y otras especies nativas; Asteraceae Subf. Asteroidae estaría conformada por varios taxones, entre ellos se menciona en la bibliografía a los cardos (Cirsium spp) y al cardo negro que podría corresponder a Cirsium vulgare, además de incluir a otras plantas tanto nativas como exóticas; los granos de polen de las Poaceae fueron divididos por tamaño, con la finalidad de separar las especies nativas $(<40 \mu \mathrm{m})$ de las especies agrícolas exóticas $(>40 \mu \mathrm{m})$, de esta forma, las Poaceae $>40 \mu \mathrm{m}$ correspondería a las plantas de cultivo de cebada (Hordeum vulgare) y de trigo (Triticum spp.) además de otras especies de menor abundancia; las Fabaceae serían la alfalfa (Medicago sativa), y los tréboles correspondientes a Trifolium repens, T. pratense, T. dubium, además de Galega officinalis y otras plantas que pudiesen ser nativas o exóticas; Rumex estaría conformado por $R$. acetosella y $R$. crispus; Rutaceae correspondería a los naranjos, limoneros y limas (Citrus spp.); Prunus serían los duraznos, melocotones, guindas y ciruelos 
(Prunus spp); Alnus probablemente corresponde a A. glutinosa; Eucalyptus debería corresponder a $E$. globulus y E. nitens principalmente; Cupressus sería C. macrocarpa; Pinus correspondería principalmente a $P$. radiata y $P$. pinaster; Acaceae serían $A$. dealbata y $A$. melanoxylon (ver tabla 1). Todos estos taxones fueron identificados por los cronistas y/o se encuentran presentes hoy en día dentro del área de estudio.

Por cada muestra se contó, un mínimo de 200 granos de polen terrestre. Es importante destacar que la vegetación nativa de la cuenca es dispersa y mayoritariamente xeromórfica. Esto explicaría la baja cantidad de polen presentes en los sedimento. Dentro del análisis de polen también se contabilizó el microcharcoal, para indicar eventos de incendios a escala regional.

\section{Análisis estadísticos}

En estos análisis se evaluaron sólo los taxones que presentaron un porcentaje $\geq 2 \%$ con la finalidad de incluir aquellos taxones que se encuentran presentes a nivel local (Lisitsyna et al., 2011; Nieto-Lugilde et al., 2015). Para distinguir diferentes asociaciones a lo largo del perfil estratigráfico se realizó un análisis cluster (CONISS) de la suma de los cuadrados de los porcentajes de los diferente grupos, para esto se utilizaron los programas Tilia y Tilia Graph (Grimm, 1987, 1991). La significancia $(p<0,001)$ del agrupamiento realizado por el CONISS se determinó con el análisis ANOSIM usando el programa Primer 6 ver. 6.1 .

\section{Análisis histórico}

Se efectuó una recopilación, selección y análisis del material bibliográfico disponible, privilegiándose la información testimonial de primer orden tales como crónicas y documentación histórica específica de los siglos XVI al XIX, que aludieran directa o indirectamente, a la situación ambiental del área de estudio. La data histórica fue complementada con información obtenida desde fuentes geográficas, historiográficas, monografías y trabajos científicos contemporáneos (desde el s.XX) aplicando el método mixto de progresión y regresión histórica (Bolós, 1992). El método mixto describe el paisaje desde la época actual a la pasada, y a la vez, reconstruye el paisaje desde un determinado momento hasta la actualidad, permitiendo el establecimiento de hipótesis de trabajo y su posible comprobación (Bolós, 1992).

\section{Resultados}

Análisis físicos y geocronológicos

El núcleo sedimentario se extrajo a 19 metros de profundidad, presentando un largo total de 185 centímetros, de los cuales solamente se analizaron los sedimentos de las profundidades 0-65 y 114$122 \mathrm{~cm}$. El sedimento fue homogéneo, compuesto casi en su mayoría por limo. En los primeros 40 centímetros el núcleo presento laminaciones. Posteriormente, el color del sedimento se homogeniza dominando el color 3/1 2,5y (Munsell Colors, 2009).

La secuencia cronológica se realizó a partir de 30 dataciones de ${ }^{210} \mathrm{~Pb}$ y una datación radiocarbónica de sedimento (Fig. 2). En base a estos valores se obtuvo el modelo cronológico que arrojó una edad total de 810 años AD para los $122 \mathrm{~cm}$ de profundidad. La tasa de sedimentación aproximada para la Laguna Avendaño fue de 1.65 $\mathrm{mm} / \mathrm{año.}$

La susceptibilidad magnética fluctuó entre 110 y $10 \mathrm{SI}^{*} 10^{-6}$, presentando los valores más altos en la línea de base y disminuyendo progresivamente hasta los centímetros más actuales. A partir del centímetro 10 (1970 AD) los valores vuelven a incrementar (Fig. 3).

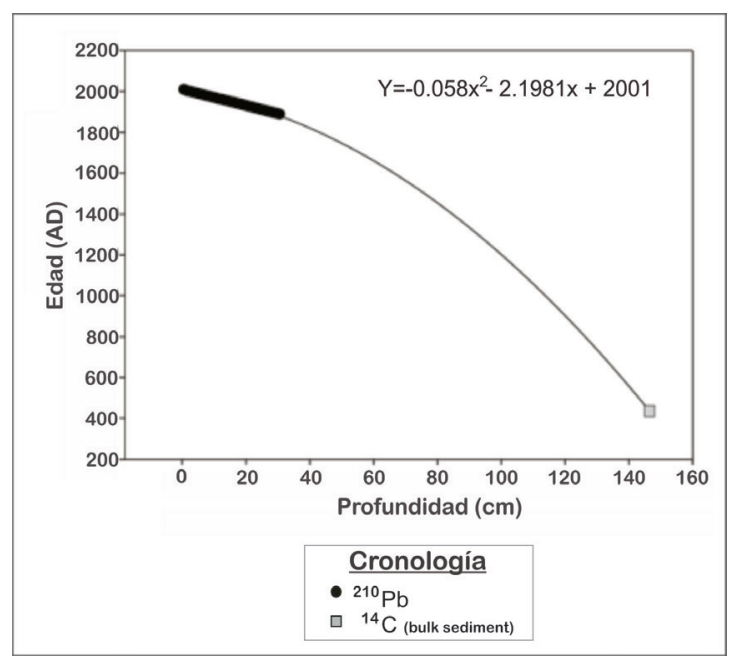

Fig. 2. Modelo de datación generado a partir de ${ }^{210} \mathrm{~Pb}$ y ${ }^{14} \mathrm{C}$, con un $\mathrm{R}^{2}=0.9$. El sedimento datado con ${ }^{14} \mathrm{C}(146.6 \mathrm{~cm})$ arrojó una edad promedio de 435 $A D ; \pm 1 \sigma=-27.5$. 
Tabla 1. Tabla comparativa de las edades de los primeros registros de las plantas exóticas identificadas en el perfil polínico y en la bibliografía.

\begin{tabular}{|c|c|c|c|c|c|c|}
\hline $\begin{array}{c}\text { Taxón exótico } \\
\text { del diagrama } \\
\text { polínico }\end{array}$ & $\begin{array}{l}\text { Taxones } \\
\text { posibles }\end{array}$ & $\begin{array}{l}\text { Edad de } \\
\text { aparición } \\
\text { en el } \\
\text { registro } \\
\text { polínico }\end{array}$ & $\begin{array}{l}\text { Edad del primer } \\
\text { registro en Chile } \\
\text { según data histórica }\end{array}$ & $\begin{array}{c}\text { Edad del } \\
\text { primer registro } \\
\text { en Chile } \\
\text { según data } \\
\text { contemporánea }\end{array}$ & $\begin{array}{c}\text { Bibliografía } \\
\text { históricas utilizada } \\
\text { (s.XVII-XIX) }\end{array}$ & $\begin{array}{c}\text { Bibliografía } \\
\text { contemporánea } \\
\text { utilizada } \\
\text { (desde el s. XX) }\end{array}$ \\
\hline \multirow{5}{*}{$\begin{array}{l}\text { Asteraceae } \\
\text { Subf. } \\
\text { Asteroidae }\end{array}$} & "Cardo negro" & \multirow{5}{*}{1610} & $1845^{\star *}$ & - & & - \\
\hline & Cirsium vulgare & & - & - & - & Matthei, 1995 \\
\hline & "Cardos" & & - & - & - & - \\
\hline & Cirsium spp & & Inicios de la conquista & - & Ovalle, 1646 & - \\
\hline & Y otros & & - & - & - & - \\
\hline \multirow{4}{*}{ Plantago } & "Plantago" & \multirow{4}{*}{1610} & $<1870$ & - & Schneider, 1904 & - \\
\hline & P. major & & - & 1847 & - & Matthei, 1995 \\
\hline & P. lanceolata & & - & 1860 & - & Matthei, 1995 \\
\hline & Y otros & & & & & \\
\hline \multirow{5}{*}{$\begin{array}{l}\text { Poaceae > } \\
40 \mu \mathrm{m}\end{array}$} & "Trigo" & \multirow{5}{*}{1610} & Inicios de la conquista** & - & Gay, 1865 & - \\
\hline & Triticum spp & & - & - & - & - \\
\hline & "Cebada" & & Inicios de la conquista & - & Gay, 1865 & - \\
\hline & $\begin{array}{l}\text { Hordeum } \\
\text { vulgare }\end{array}$ & & $\mathrm{cos}$ & - & 年 & - \\
\hline & Y otros & & & & & \\
\hline \multirow{10}{*}{ Fabaceae } & “Trébol” & \multirow{10}{*}{1610} & Inicios de la conquista & - & Ovalle, 1646 & - \\
\hline & "Trébol francés" & & $\sim 1850^{* *}$ & - & Gay, 1865 & - \\
\hline & $\begin{array}{l}\text { Trifolium } \\
\text { pratense }\end{array}$ & & 1870 & 1930 & Schneider, 1904 & Matthei, 1995 \\
\hline & T. repens & & 1870 & 1897 & Schneider, 1904 & Matthei, 1995 \\
\hline & T. dubium & & 1870 & 1897 & Schneider, 1904 & Matthei, 1995 \\
\hline & "Alfalfa" & & Inicios de la conquista** & - & Gay, 1865 & - \\
\hline & Medicago sativa & & - & 1874 & - & Matthei, 1995 \\
\hline & "Galega" & & $\sim 1850$ & - & Schneider, 1904 & - \\
\hline & Galega officinalis & & - & 1881 & - & Matthei, 1995 \\
\hline & Y otros & & & & & \\
\hline \multirow[t]{2}{*}{ Rumex } & R. acetosella & \multirow[t]{2}{*}{1615} & $\sim 1750^{*}$ & 1851 & $\begin{array}{l}\text { Fletcher y Moreno, } \\
\qquad 2012\end{array}$ & Matthei, 1995 \\
\hline & R. crispus & & - & 1851 & - & Matthei, 1995 \\
\hline Rutaceae & Naranjos & \multirow{2}{*}{1620} & Inicios de la conquista & \multirow{3}{*}{-} & Ovalle, 1646 & - \\
\hline (Citrus spp) & Limoneros... & & Inicios de la conquista & & Ovalle, 1646 & - \\
\hline \multirow{4}{*}{ Prunus } & Duraznos & \multirow{4}{*}{1730} & Inicios de la conquista & & Ovalle, 1646 & - \\
\hline & Guindas & & Inicios de la conquista & - & Ovalle, 1646 & - \\
\hline & Cerezas & & Inicios de la conquista & & Ovalle, 1646 & - \\
\hline & Almendros & & Inicios de la conquista & & Ovalle, 1646 & - \\
\hline Alnus & A. glutinosa & 1900 & $<1893$ & 1869 & $\begin{array}{l}\text { Quinta Normal de } \\
\text { Agricultura, } 1893\end{array}$ & $\begin{array}{l}\text { Fuentes et al., } \\
2014\end{array}$ \\
\hline \multirow{2}{*}{ Acacia } & A. dealbata & \multirow{2}{*}{1870} & - & 1869 & C & $\begin{array}{l}\text { Fuentes et al., } \\
\qquad 2014\end{array}$ \\
\hline & A. melanoxylon & & - & 1923 & - & $\begin{array}{l}\text { Fuentes et al., } \\
2014\end{array}$ \\
\hline \multirow{2}{*}{ Eucalyptus } & E. globulus & \multirow{2}{*}{1870} & $<1881^{* *}$ & - & Schneider, 1904 & - \\
\hline & E. diversicolor & & - & - & - & - \\
\hline \multirow{2}{*}{ Cupressus } & "Cipreses" & \multirow{2}{*}{1830} & $<1881^{* *}$ & - & Schneider, 1904 & - \\
\hline & C. macrocarpa & & - & - & - & - \\
\hline \multirow{3}{*}{ Pinus } & "Pino marítimo" & \multirow{3}{*}{1850} & $1865^{\star *}$ & - & Schneider, 1904 & - \\
\hline & $P$. insigne & & - & 1885 & - & Matthei, 1995 \\
\hline & P. radiata & & - & - & - & - \\
\hline
\end{tabular}

${ }^{*}$ ) Edad obtenida a partir de registros paleolimnológicos.

$\left.{ }^{* *}\right)$ Edades del primer registro en la Región del Bio-Bio.

$(<)$ Especies que a esa fecha ya presentaban una amplia distribución.

( $Y$ otros), Dentro de este taxón también se podrían encontrar otras especies de la misma familia, tanto nativas como exóticas. 


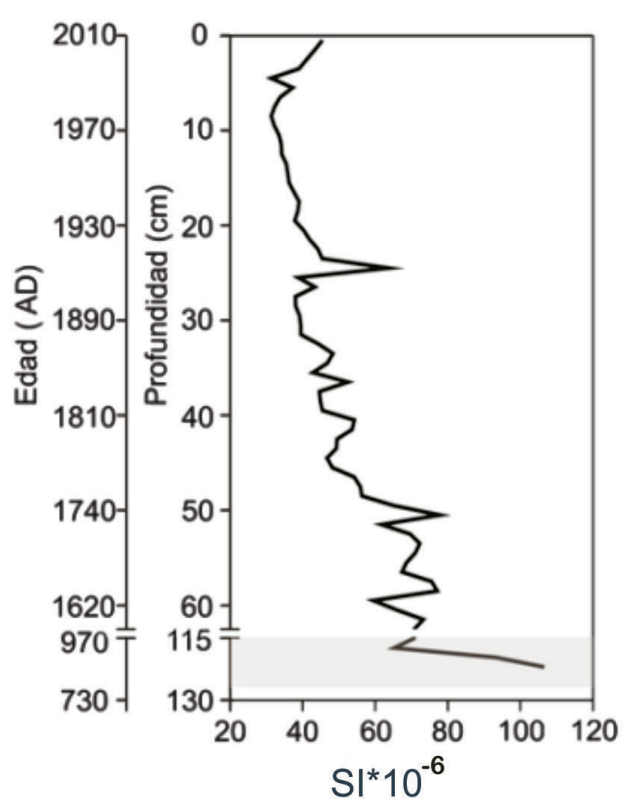

Fig. 3. Susceptibilidad magnética, en el gráfico se señala además la línea de base correspondiente a la parte más profunda del registro (centímetros 114122; correspondiendo a 130 años).

\section{Polen}

Se encontró un total de 59 taxa en los registros sedimentarios, de los cuales se identificaron 25 plantas exóticas, 23 nativas y 11 taxones que tienen distribución tanto en Chile como en países nórdicos. Luego de la selección de los taxones con abundancias superiores al $2 \%$, el ensamble polínico finalmente quedó constituido por 31 taxa, de los cuales los más abundantes fueron Pinus, Poaceae $(<40 \mu \mathrm{m}$ y $>40 \mu \mathrm{m})$ y Plantago. La secuencia de polen fue dividida en tres zonas $(1,2 \mathrm{a} ; 2 \mathrm{~b}$ y 3 ) respetando los clusters obtenidos en el análisis CONISS (Fig. 4 y 5).

Zona 1, (810-970 AD; Situación prehispánica). El ensamble polínico fue dominado por Poaceae $<40 \mu \mathrm{m}$ (35-60\%), seguidos por Asteraceae Subf. Asteroidae, con un $15 \%$. Entre los taxones nativos sólo Nothofagus dombeyi-type, Anacardiaceae y Cryptocarya alba alcanzaron el $10 \%$ en su abundancia, el resto de los taxa nativos presentaron valores cercanos al 5\%. Las concentraciones fluctuaron entre 140000 y 3300 granos $/ \mathrm{ml}$, donde los valores más altos correspondieron a Poaceae < $40 \mu \mathrm{m}$. La concentración promedio de microcharcoal fue 710600 partículas/ml (Fig. 5).

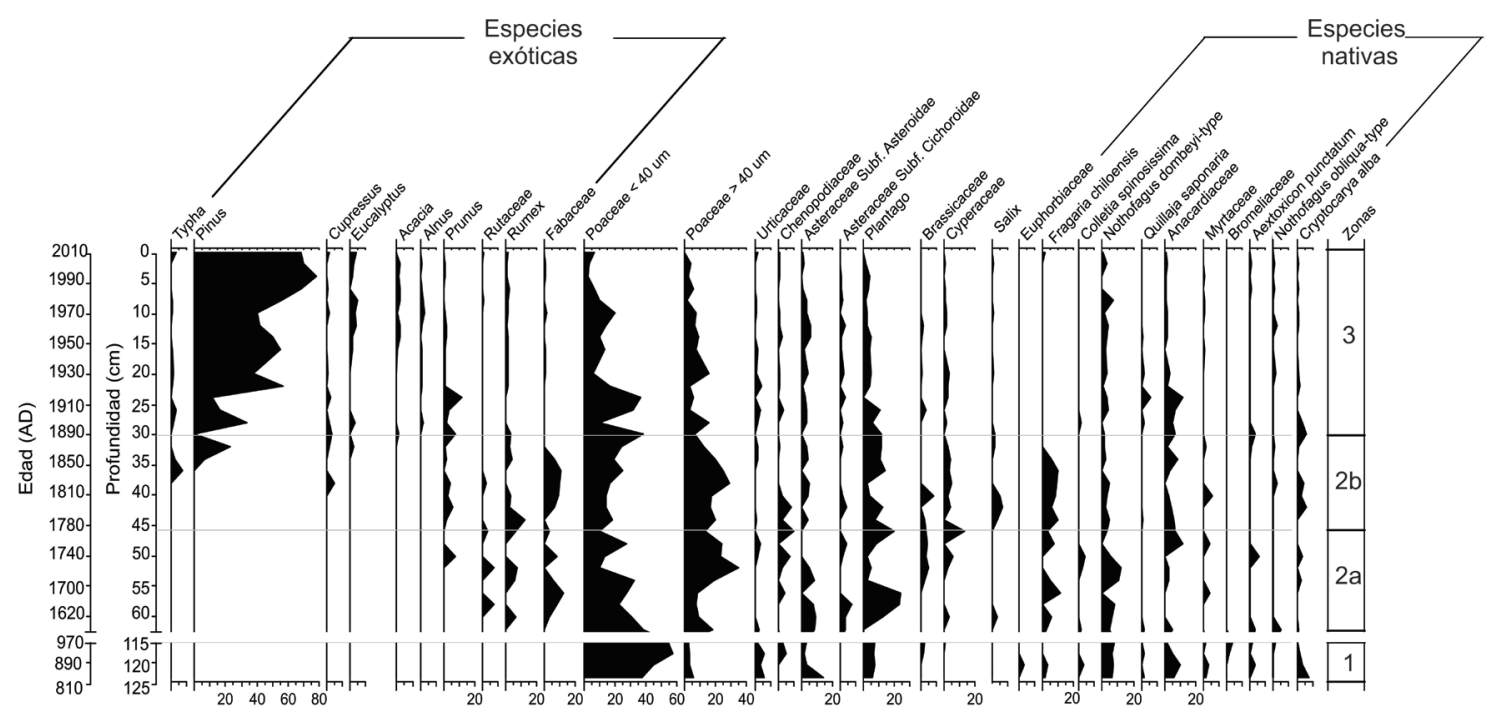

Fig. 4. Diagrama polínico de abundancias relativas (\%). En el diagrama se hace la distinción entre taxones exóticos y nativos, se señalan las zonas obtenidas a partir del análisis CONISS y se diferencia la línea de base o Situación prehispánica, que corresponde a la Zona 1 del perfil. 

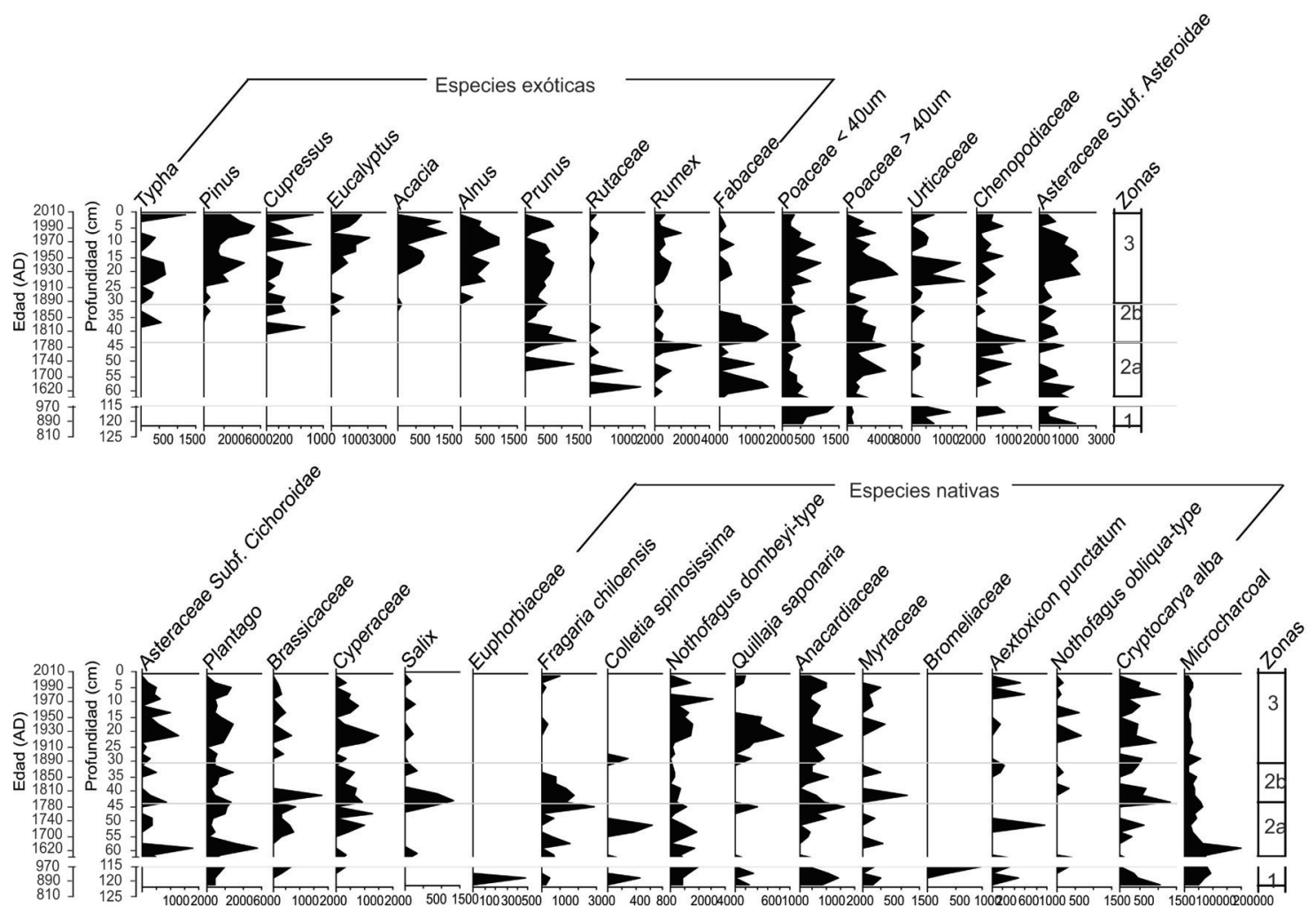

Fig. 5. Diagrama polínico de abundancias totales. En el diagrama se señalan además las concentraciones de microcharcoal y la línea de base correspondiente a la Zona 1.

Zona 2, (1610-1890 AD; Auge agrícolaganadero). A partir de los clusters generados en el análisis CONISS, esta zona se pudo dividir dos subzonas: 2a (1610-1780 AD) y 2b (1780-1890 $\mathrm{AD})$. En $2 \mathrm{a}$, las Poaceae $<40 \mu \mathrm{m}$ disminuyeron con respecto al final de la zona anterior y las Poaceae $>40$ $\mu \mathrm{m}$ incrementaron un $15 \%$ alcanzando su máximo alrededor de $1720 \mathrm{AD}$, mientras que Plantago presentó las abundancias más altas al comienzo de esta zona (20\%). Incrementaron además las Cyperaceae, Brassicaceae y Fragaria chiloensis. Entre los taxa arbóreos se identificó un aumento de $N$. dombeyi-type a un $15 \%$ y una reducción de Anacardiaceae al comienzo de este periodo. Bromeliaceae y Euphorbiaceae desaparecen del registro polínico, mientras que el resto de las plantas nativas presentan valores fluctuantes inferiores al $5 \%$. Dentro de esta subzona aparecen los primeros taxa exóticos, Prunus, Rutaceae, Rumex y Fabaceae, siendo este último taxón el que presento los valores más altos (15\%; Fig. 4). Las concentraciones de los taxones fluctuaron entre 0 y 30000 granos $/ \mathrm{ml}$; el microcharcoal presentó una concentración promedio de 505670 partículas $/ \mathrm{ml}$, registrando los valores más elevados al comienzo de éste periodo (Fig. 5). En $2 \mathrm{~b}$, las Poaceas $>40 \mu \mathrm{m}$ siguen manteniendo altas abundancias, mientras que el resto de los taxones de amplia distribución no presentan mayores variaciones. Entre las plantas nativas N. dombeyi-type y Anacardiaceae disminuyen de un $15 \%$ a un $10 \%$. Los otros taxa no presentaron cambios. Dentro de esta subzona aparecen nuevas plantas exóticas: Acacia, Eucalyptus, Cupressus, Typha y Pinus, siendo esta última la que tiene las abundancias más importantes (20\%). Las concentraciones polínicas fluctuaron entre 0 y 15000 granos/ml, mientras que el microcharcoal no supero las 25000 partículas $/ \mathrm{ml}$.

En la Zona 3 (1890-2010 AD; Periodo forestal), el ensamble polínico presentó las mayores variaciones del perfil. Las abundancias de la mayoría de los taxones de amplia distribución disminuyeron considerablemente a valores inferiores al $10 \%$. Los 
taxa más afectados fueron Poaceae $>40 \mu \mathrm{m}$, Plantago, F. chiloensis, Anacardiaceae, Fabaceae, Rumex y los frutales. La única especie nativa que presentó cierto incremento al inicio de este periodo, fue Quillaja saponaria. Mientras que la mayor parte de los árboles forestales incrementaron sus porcentajes, siendo Pinus la planta dominante, alcanzando un $80 \%$ en 1990 (Fig.4). Las concentraciones polínicas fluctuaron entre 548780 y 0 granos $/ \mathrm{ml}$ y el microcharcoal presentó las concentraciones más bajas de todo el perfil $($ promedio $=225640$ partículas $/ \mathrm{ml})$.

El análisis ANOSIM mostró diferencias significativas entre las diferentes zonas identificadas por el CONISS. El resultado fue un $\mathrm{R}$ Global $=0.7$ y una significancia de $p=0.001$. Las comparaciones pareadas entre las zonas también presentaron diferencias significativas $(\mathrm{R}$ zonas $[3 / 2]=0.7, p=$ $0.001 ; \mathrm{R}$ zonas $[3 / 1]=0.7, p=0.001 ; \mathrm{R}$ zonas $[2 / 1]$ $=0.4, p=0.001$ ).

\section{Análisis histórico}

Muchos eventos y procesos influyeron en la transformación del paisaje del valle del Itata, debido a esto la historia ambiental de la cuenca fue dividida en tres periodos: i) Situación prehispánica, se describe el paisaje existente a la llegada de los españoles; ii) Periodo de auge agrícola-ganadero, se analiza la introducción de las primeras especies biológicas europeas y el uso del territorio y iii) Periodo forestal, desarrollo de las primeras plantaciones de árboles exóticos.

\section{Situación prehispánica}

La primera expedición al sur de Santiago fue realizada en 1546, por el Conquistador Pedro de Valdivia (Villalobos, 1995). Durante esta exploración Gerónimo de Bibar, soldado y cronista participante de los hechos, describe las condiciones ambientales que observó en el valle del Itata: "desde el valle de Maule hasta el valle de Itata es del temple del Mapocho, y de aquí comienza otro temple, que hay invierno y verano y llueve más y los vientos más furiosos. No es de regadío y los bastimentos serían con el agua que reciben de invierno. De este valle Itata no hay algarrobas ni espinos de los que dicho tengo de Mapocho, y desde el valle Copiapó hasta este valle. De la Cordillera nevada no es montuosa sino pelada, y desde aquí adelante va montuosa de muy grandes árboles" (Bibar, 1966).
Tres siglos después, en 1828, el naturalista Eduard Pöeppig (1960) describe el valle del Itata como una zona muy pobre en vegetales y menciona algunas especies presentes en lugar como el pichepiche [Fabiana imbricata], algunos arbustos del género Senecio y a Opuntia caspitosa Poepp. [Maihuenia poeppigii] (Pöeppig, 1960). Más tarde, Karl Reiche (1934-1937) botánico alemán, complementa la descripción hecha por Pöeppig señalando que Acacia cavenia [Acacea caven], muy abundante en el norte disminuye mucho en esta zona. Además agrega que en esta cuenca hay unos suelos arenosos y estériles que cubren todo el valle central desde la Cordillera de la Costa hasta los Andes, y entre el río Itata y el Laja. En ciertas partes presenta arenales casi sin vegetación, mientras que en otras hay matorrales xerófitos de Quillaja saponaria, Lithraea caustica, Schinus dependens, Baccharis rosmarinifolia, Fabiana imbricata y Colletia spinosa [Colletia spinosissima]. Según el mismo autor, otras especies que se encontraban comúnmente en la zona eran Wahlenbergia linarioides, Haplopappus acerosus, Calandrinia serícea, Chaetanthera serrata, Panicum d'Urvilleanum [Panicum urvillenum], Aristida pallens, Carex berteroana y Aira cariophyllea (Reiche, 1934-1937).

De acuerdo a las descripciones anteriores se deduce que el valle del río Itata era entonces un llano provisto con vegetación xeromórfica, pobre en especies. Se caracterizaba por la presencia del matorral y bosque esclerófilo, con una alta representatividad de Quillaja saponaria, Cryptocarya alba, Fabiana imbricata, Colletia spinosissima y una menor representación de Acacea caven. Gracias a la descripción de Bibar (1966), también se puede señalar que las quebradas y los cerros presentaban una vegetación boscosa, probablemente con un bosque caducifolio templado, con dominancia de laureles, arrayanes, robles y olivillos, muy similar al que hoy en día encontramos en las zonas altas de los cerros cercanos a Quillón, que aún mantienen vegetación nativa.

\section{Periodo de auge agrícola-ganadero}

Con la irrupción de los conquistadores al territorio se inició un largo período de enfrentamiento entre mapuches y españoles, conocido como "La Guerra de Arauco", que se extendió por casi tres siglos. Durante este conflicto alternaron periodos de enfrentamientos dónde prevaleció la devastación del territorio, con largos episodios de paz, donde surgía un atractivo 


\section{P. Vargas et al. - Rápido movimiento de plantas exóticas en Chile Central}

comercio basado principalmente en el intercambio de semillas y animales, actividad conocida como trueque (Villalobos, 2013).

Con la finalidad de ir consolidando y protegiendo el territorio, los españoles comienzan a fundar poblados y fuertes (Bibar, 1966; Guarda, 1990; Molina, 1795). En 1550, se funda el fuerte y la ciudad de La Concepción de la Nueva Extremadura, en el sitio de la actual ciudad de Penco. Posteriormente en 1579 se establece el fuerte y ciudad de Chillán, situada en el valle central a los pies de la cordillera (Molina, 1795; Villalobos, 2013). Poco más tarde, se inician las misiones evangelizadoras de la Compañía de Jesús y la Orden de San Francisco, las que establecieron diferentes estancias o haciendas dentro del conflictivo territorio (Bibar, 1966; Molina, 1795; Orellana, 1992). Entre estas nuevas haciendas encontramos la de Buena Esperanza o Rere (a partir de 1603), y los primeros predios jesuitas (desde 1617). Tanto La Concepción como Chillán tenían profunda relación con el área rural, y fueron lugares de residencia de ricos propietarios agrícolas y/o ganaderos; además fracciones significativas de sus pobladores, trabajan en las chacras de los alrededores de la ciudad y en las tierras más distantes destinadas a la cría de ganado (Cunill, 1971; Villalobos, 2013). Durante todo este periodo hubo importantes alzamientos indígenas que provocaron la destrucción de varias ciudades las que fueron abandonadas y posteriormente repobladas. La última sublevación importante fue en 1723, pocos años después comienzan las conversaciones de paz para poner fin al conflicto (Molina, 1795; Villalobos, 2013). Finalizada la guerra se fortalece la iniciativa colonizadora de esta región. Así desde 1770 "cada soldado, con una cantidad de años que lo convertía en un veterano, tenía derecho a recibir 25 cuadras de tierra agrícola y las vacas sin dueño que contenían" (Orellana, 1992). De esta manera fue ocupándose el territorio con nuevos hacendados que se enriquecerían gracias a la agricultura y la ganadería (Cunill, 1971; Guarda, 1968).

Durante el proceso de colonización los españoles traían consigo diferentes elementos de Europa, como animales domésticos, trigo, cebada, legumbres, frijoles y muchas otras semillas necesarias para facilitar su existencia en tierras desconocidas (Ovalle, 1646; Torrejón \& Cisterna, 2002), las que se propagaban en las diferentes provincias a medida que estas eran ocupadas. En este sentido, Gay (1862) señala: "desde los primeros tiempos de la conquista vemos en efecto cultivarse muchas legumbres, plantas industriales y poco después el moral [Rubus constrictus o $R$. ulmifolius]". Durante el proceso temprano de ocupación del territorio, "pusieron igualmente gran empeño en propagarse arboles frutales en sus chacras llegadas á ser verdaderas huertas, los que gracias á la excelencia del clima se multiplicaban bien pronto al infinito". Señalando además que a fines del siglo XVI todos los frutos de la vieja Europa se encontraban en abundancia. De igual manera, Ovalle (1646) menciona en detalle las plantas europeas que ya habían sido introducidas y expandidas en tierras chilenas "porqueantes que los Efpañolesla conquiftaffen, no hauia en toda ella viñas, Higueras, Olivos, Manzanos, Camueços, Melocotones, Duraznos, Alberchigos, Mémbrillos, Peras, Granadas, Guindas, Albarcoques, Ciruelas, Naranjas, Limas, Limones, Cidros. Almendros: y delas femillas tan poco hauia el trigo, la cenada, el Anis, el Culantro, los cominos, y el Oregano, ni Lino, ni Cañamo, ni Garbanços, Alvergas, ni Auas delas plantas no fe que huuieffe Lechugas, Coles, Rabanos, Cardos, Efcarplas, Verengenas, Sanahorias, Calabaças delas que llaman de Caftilla, Melones, Cohombros, y Sandias, Peregil, ajos, ni Ceuollas."

De estas especies es importante destacar el trigo, cuyo uso se generalizo (Cunill, 1971; Gay, 1865; Schneider, 1904). En la región se habría introducido con las primeras expediciones españolas, para cultivarse en torno a los fuertes y abastecer así a las guarniciones (Gay, 1862). Además, esta gramínea también era cultivada a nivel local en las diferentes haciendas o estancias que habían en el valle del Itata, y gracias a su rápida adaptación al suelo y clima, no tardó en multiplicarse (Ovalle, 1646; Molina, 1788). Sumado a esto, a partir de 1687 se inició la exportación masiva de este cereal al Perú, como resultado del terremoto ocurrido en Lima y de una peste que afectó a los cultivos de este grano (Cunill, 1971). Este hecho transformó la economía rural del valle central chileno, generando importantes transformaciones del paisaje y una intensificación en el uso del suelo (Cunill, 1971; Villalobos, 2013). Entre 1695 y 1696 , se duplicaron las siembras del cereal en la región. Era tal la conveniencia de la exportaciónes de trigo que existió "lo que puede denominarse una fiebre del trigo" ya que, se pedían cada vez más mercedes de tierra en los partidos de Itata, Puchacay, Rere y Chillán, donde se llegaba a sembrar incluso en los caminos (Cunill, 1971). Si bien, a fines del siglo 
XVII se inician masivas producciones de trigo en la zona central, hay evidencia que indica que éstas ya habrían comenzado a inicios de aquel mismo siglo, en algunas estancias jesuitas y en Rere (Gay, 1865).

A las especies ya mencionadas se suma también la viña la cual, al igual que el trigo, se cultiva desde tiempos remotos. No se sabe con exactitud en qué época fue introducida, pero en las cartas de Valdivia vemos que en 1551, diez años después de su llegada a Chile, las uvas se comían en Santiago y en Serena (Gay, 1862). Los cultivos, se extendieron también con prontitud ya que "las vides fructifican prodigiosamente en todo el Reyno de Chile", indicándose también que "las uvas que se maduran en las márgenes del río Itata producen el mejor vino de todo Chile" (Molina, 1788).

El desarrollo agrícola alcanzado, a fines del s. XVII y principios del s. XVIII, llevó a una creciente necesidad de mano de obra la que era suplida por los indígenas (Cunill, 1971), quienes conocían muy bien las técnicas de cultivo de estas especies exóticas, ya que las habían adoptado tempranamente en el proceso de colonización (Gay, 1865; Torrejón \& Cisterna, 2002). Antes de la llegada de los españoles los nativos tenían una agricultura basada en el maíz [Zea maíz], el madi [Madia sativa], las papas [Solanum tuberosum], los frijoles [Phaseolus vulgaris], el mango [Bromus mango], la quínoa [Chenopodium quinoa] y las fresas [Fragaria chiloensis] (Cunill, 1971; Molina, 1788; Ovalle, 1646). Sin embargo, su cultivo fue muy pronto abandonado y reemplazado por el trigo, la cebada y otras especies foráneas (Gay, 1865).

Menos de un siglo perduró la relativa tranquilidad en la región, pues en 1813 comienza la "Guerra de la Independencia" (Molina, 1795; Villalobos, 2013). Durante este proceso todo el país se movilizo "al grito de la Patria, de la justicia y de la razón se conmovieron todos los hacendados abandonando sus campos, sus útiles los cultivadores" (Gay, 1862). Los puertos de Valparaíso y Concepción, abiertos en 1778 para fines comerciales, fueron bloqueados en 1811, debido a la baja productividad del país y al cese de las exportaciones.

Chile se independiza a inicios del s. XIX. En este marco surge un espíritu constante superación y desarrollo intelectual (Gay, 1862), situación reforzada aún más con la inauguración del jardín botánico en 1853 y la interacción con instituciones extranjeras (Quinta Normal de Agricultura, 1893). Lo anterior conllevo a la introducción de nuevas especies de plantas con el principal objetivo de generar conocimientos botánicos para la horticultura, medicina, silvicultura, y/o agricultura (Arroyo et al., 2000). Así, en mayo de 1884, ya habían introducido 2196 especies, pertenecientes a 166 familias. La finalidad de este jardín y de la Quinta Normal, era mejorar la calidad de vida de las personas, por ello a las plantas introducidas se les realizaban diferentes pruebas o tratamientos para evaluar sus beneficios, y una vez que estos eran corroborados, se vendían y distribuían a la población (Quinta Normal de Agricultura, 1893). De este modo, en el catálogo del año 1893 encontramos 350 variedades de plantas y/o semillas (árboles y arbustos, hortalizas, plantas bulbosas, cereales, etc), que fueron puestas a la venta. La introducción de especies continuó desmesuradamente llegando a más de 3000 especies (Marticorena \& Rodríguez, 1995), muchas de las cuales se encuentran hoy en día naturalizadas y distribuidas ampliamente por el país (Pauchard et al., 2011).

Durante este mismo periodo ocurren dos eventos importantes que beneficiaron aún más el desarrollo económico y la introducción y dispersión de especies. En primer lugar se desarrollaron las vías de transportes, pues a mediados de este siglo ya existían líneas de tren y carreteras que conectaban la parte sur del valle central con Santiago (Gay, 1862, 1865). El segundo evento es conocido en la historia como "La fiebre del oro", un periodo de gran migración de trabajadores a los lavaderos de oro de California y más tarde a los de Australia (Schneider, 1904). Estos acontecimientos revolucionaron la agricultura del valle central de Chile. El cultivo del trigo que anteriormente se hacía para abastecer el consumo interior, el del Perú y otros mercados de menores, se incrementó progresivamente (Cunill, 1971; Mackenna, 1867). Según las estadísticas entregadas por Schneider (1904), en 1845 las exportaciones de trigo alcanzaron los 4.569.986 kilos, cifra que se sobrepasó 25 veces en 1870. El crecimiento de la producción cerealera va perdurar hasta 1887 . Sin embargo, las provincias situadas en el sur del valle central, fueron afectadas por lluvias torrenciales durante 1870 , posteriormente siguieron dos periodos de malas cosechas y más tarde, en 1893, hubo una importante sequía, generando pérdidas importantes de producción triguera. Pese a lo anterior, en 1903 se vuelven a registrar producciones importantes en la zona sur (Schneider, 1904). 


\section{P. Vargas et al. - Rápido movimiento de plantas exóticas en Chile Central}

Si bien, las provincias situadas en la parte sur del valle central se caracterizaban por una alta productividad agrícola, estas no presentaban una fertilidad tan alta como las tierras situadas entre Santiago y el Maule (Camus, 2006; Gay, 1862; Mackenna, 1881), es por ello que Poeppig (1960) describe la zona del Partido de Rere como "poco favorecida por la naturaleza, donde los cereales dan sólo un $25 \%$ más de la cantidad sembrada". Lo anterior habría conllevado a que muchas haciendas situadas entre el río Maule y el Bio-Bio se dedicaran a la ganadería, cuya producción abastecía el mercado del Perú de sebo, cordobanes y media suela (piezas de cuero para el calzado) entre otros productos, además de alimentar al ejército español (Cunill, 1971; Molina, 1795). Entre los cultivos forrajeros utilizados inicialmente, está la alfalfa, la cual "ha sido la sola planta cultivada para las praderas, pero de algunos años por acá se ha introducido el trébol, planta mucho mas adecuada á los climas lluviosos del Sur y que se cultiva ya en grande en la provincia de Concepción en donde esta conocida con el nombre de trébol francés" (Gay, 1865). El mismo autor menciona además que anteriormente se sembraba también el cardo [Cirsium spp]. Entre las plantas forrajeras destaca el cardo negro [C. vulgare o C. acaule] maleza introducida en el año 1845 por el Señor Ricardo Price en su hacienda situada en Chillán. Debido a sus características de invasora no tardo en generalizarse y al poco tiempo ya se encontraba desde Llanquihue al norte (Schneider, 1904). Otra planta traída al país como forrajera es la Galega [Galega officinalis], que ha invadido los terrenos regados con las aguas del estero de la Angostura de Paine y las orillas del río Maipo. Más tarde, en el año 1870, se introdujeron las semillas del trébol rosado, blanco, amarillo [Trifolium pratense, T. repens y T. dubium, respectivamente] y el Ray grass [Ballica inglesa]. A diferencia de las especies anteriores la semilla del Plantago, otra maleza ampliamente dispersada por las praderas de las regiones del centro, se introdujo accidentalmente mezclada con las de plantas forrajeras (Schneider, 1904).

Aunque estas plantas se cultivaban, es probable que se hallan asilvestrados, multiplicado y expandido rápidamente por el país debido a las favorables condiciones del territorio, en este sentido Ovalle (1646) indica lo siguiente: "la Moftaça, nabo, yeruabuena, hinojo, y trébol, y otras que en Europa veo fembrar, y cultiuar, por la debida eftima que de ellas fe haze, nacen en Chile por los campos fin ningún beneficio humano, y con tanta abundancia que algunas de ellas fe continúan por muchas leguas, y fon el pafto meas commun de los ganados". Así mismo, Gay (1862) señala que en 1859 las provincias de Cauquenes, Chillán y Concepción, eran las que alimentaban "los más crecidos ganados de la República y desde estos puntos se los llevaban cuando estaban ya cebados a las provincias del centro".

\section{Periodo forestal}

Debido a la intensa producción agrícola de los siglos XVI, XVII y XVIII, muchos bosques fueron eliminados utilizando el llamado roce, operación que consistía en cortar los árboles y dejarlos secar sobre el mismo terreno para posteriormente quemarlos. Sobre estas cenizas se sembraba el trigo que proporcionaba considerables cosechas (Camus, 2006; Gay, 1865). Esta actividad genero una importante reducción de los bosques, lo que sumado a la explotación de madera para la construcción y la leña, llevo al Gobierno en el año 1872 a promulgar las primeras leyes para proteger al bosque nativo (Otero, 2006; Schneider, 1904). El consumo de madera era cada vez más importante y costoso debido al crecimiento de las ciudades y al incremento de las distancias entre las zonas de extracción y las de consumo (Camus, 2006; Otero, 2006). En 1889 el Consejo de la Quinta Normal establece la conveniencia de instaurar las plantaciones, tanto como de árboles forestales como de frutales (Schneider, 1904). Las iniciativas para introducir especies arbóreas se hicieron más numerosas a fines de la década de 1830. En 1839 Carlos Durant Maison, miembro de la Sociedad de Agricultura, envío a Pedro Mena, director de la Sociedad de Agricultura, un cajón que contenía más de cien semillas europeas, con la finalidad que las especies más interesantes se propagasen. Así, a principios de 1840 la Sociedad Agrícola realiza los primeros proyectos para introducir especies exóticas, con el objetivo de suplir las crecientes demandas de madera (Camus, 2006; Schneider, 1904). "El proceso inicial de introducción de especies forestales fue lento y uno de los primeros en iniciarlas fue el señor De la Porte, quien en 1865 plantó pinos en los terrenos arenosos, casi inútiles de los márgenes del río Itata. Multiplicó de preferencia el pino marítimo [Pinus pinaster] obteniendo muy buenos resultados, logrando árboles que a los quince años 
median 1.60 m" (Schneider, 1904). En 1881 había también plantaciones de pino en las quintas y cerros inmediatos a Concepción, en la desembocadura del río Bio-Bio, y en Lota (comuna de la Región del Bio-Bio), lugares donde también se podían encontrar cipreses, encinas y Eucalyptus globulus (Camus, 2006; Schneider, 1904).

En las décadas siguientes las plantaciones de árboles exóticos fueron en aumento, tanto así que en el año 1904 el Ministerio de Industria y Obras Públicas, publica "el Plan Jeneral para el Cultivo de Bosque", donde se describen las especies forestales más adecuadas para cada zona del país y las condiciones en que estas debieran ser plantadas para maximizar su producción (Albert, 1907). Fueron 15 los árboles descritos en este trabajo: Acacia melanoxylon, Cupressus macrocarpa, Cupressus torulosa, Eucalyptus diversicolor, Eucalyptus globulus, Eucalyptus resinifera, Eucalyptus robusta, Eucalyptus viminalis, Punus canariensis, Pinus insignis [Pinus radiata], Pinus maritima [Pinus pinaster], Quercus pedunculata [Quercus robur], Quercus sessiliflora [Quercus petraea], Robinia pseudoacacia y Sequoya sempervirens. Algunas de estas especies forestales fueron tan exitosas que se expandieron masivamente desde Copiapó hasta el sur de Chile.

Entre los años 1860 y 1900 ocurrieron dos eventos demográficos importantes: el incremento de la población en todas las zonas pobladas que conllevó al aumento, aún más fuerte, en la demanda de madera, y un éxodo desde los campos hacia las ciudades que dejo terrenos aptos disponibles para la silvicultura (Ruiz-Tagle, 1966). Sumado a esto, a partir del siglo XX muchos suelos de cultivo de Chile central comenzaron a empobrecerse debido a la intensiva actividad agrícola, que venía desarrollándose desde el siglo XVI (Aguayo et al., 2009). Como una medida de gestión, el Gobierno chileno incentivó la repoblación forestal favoreciéndose a las especies de rápido crecimiento (Albert, 1906; Camus, 2006). Desde los inicios del siglos XX y hasta la actualidad, destaca la Región del Bio-Bio como centro de las actividades forestales y madereras derivadas de las plantaciones de Pinus radiata, E. globulus y E. nitens, presentando una superficie de 749.593 ha de plantaciones forestales, las cuales se distribuyen entre las provincias de Concepción, Bio-Bio, Ñuble y Arauco, con un 16\%, 30\%, 27\% y 27\% respectivamente (Camus, 2006; INE, 2007; Frêne \&
Núñez, 2010).

\section{Discusión}

Durante los últimos 500 años el registro polínico mostró episodios importantes de producción agrícola, ganadera y forestal que estuvieron asociados a la introducción de diferentes especies de plantas. En la información histórica recopilada se mencionan varias especies exóticas, muchas de las cuales fueron identificadas dentro de la parte sur del valle central e incluso dentro de la cuenca del río Itata. No obstante, no todas estas fueron registradas en el perfil polínico. Esto no significa que las especies mencionadas no hayan estado presentes dentro de la cuenca de estudio, sino que más bien, esta ausencia respondería a la baja producción polínica de estas especies y/o a su mecanismo de dispersión (Odgaard, 2013).

\section{Introducción de especies para fines agricolas}

En los inicios del siglo XVII, a partir de la temprana ocupación del territorio, se evidencian inmediatamente en el registro polínico los primeros efectos del asentamiento español, asociados al roce o al despeje de tierras para habilitar terrenos para la agricultura (ver microcharcoal Fig. 5). El cual debió ser más intenso a los inicios de la ocupación regional, lo que explicaría las altas concentraciones de michocarcoal registradas alrededor de 1620. Posteriormente se evidencia el cultivo intensivo de cereales, situación que ha sido mencionada ampliamente por varios autores (Camus, 2006; Cunill, 1971; Donoso \& Lara ,1996; Torrejón \& Cisterna, 2002). La actividad agrícola de la cuenca del río Itata habría afectado más a las praderas naturales de la zona, que a los bosques. Lo anterior se evidencia al comparar la línea de base o la Situación prehispánica con el Periodo de auge agrícolaganadero. Dónde se refleja una reducción de las Poaceae nativas (Poaceae $<40 \mathrm{um}$ ) y una mínima variación en los valores de los taxones arbóreos nativos (Fig. 4 y 5).

Según los primeros cronistas que reconocieron el territorio, antes de las intensas actividades agrícolas y ganaderas, el valle del río Itata habría tenido una vegetación muy escasa por ser una zona árida con suelo arenoso, que no favorecía mayormente la presencia de bosque, sino más bien eran pequeñas agrupaciones de L. caustica y $Q$. saponaria acompañadas de algunas plantas xerofitas como $C$. spinosissima (Reiche, 1934-1937; Poeppig, 1960; 


\section{P. Vargas et al. - Rápido movimiento de plantas exóticas en Chile Central}

Bibar, 1966), situación muy similar a la que hoy en día encontramos en la parte Noroeste del litoral del lago, en donde también podemos hallar diversas especies de herbáceas de las Familias Brassicaceae, Asteraceae y por sobre todo Poaceae.

Las exportaciones al Perú favorecieron la producción de trigo de toda la región. Hecho que se ve reflejado en el perfil polínico con un incremento en las abundancia de las Poaceae $>40 \mu \mathrm{m}$, que comienza alrededor de 1700 y con un máximo en $\sim 1730$ (Fig. 5). Posteriormente, la abundancia de estas plantas disminuye. Inicialmente, esta situación habría sido causada por el abandono de las chacras durante la Guerra de la Independencia (1810 1818). Con la finalización de los conflictos bélicos que afectaron mayormente a esta zona, nuevamente se generó un aumento en la producción de trigo, reflejado por el incremento de las Poaceae $>40 \mu \mathrm{m}$ alrededor de 1840, señal de que los campos habrían vuelto a ser ocupados y cultivados. A mediados del s. XIX comienza otro periodo de auge agrícola asociado a la producción de este cereal conocido como la fiebre del oro (Schneider, 1904). No obstante, debido a la sobre explotación de la zona en los siglos anteriores y a desfavorables condiciones climáticas, ésta no tuvo el mismo protagonismo dentro de la economía agrícola nacional (Mackenna, 1881; Schneider, 1904).

Dentro de las chacras de la época (XVII), además del cultivo de cereales, se realizaban también desde muy temprano, los cultivos de árboles frutales (Ver tabla 1; Gay, 1862; Ovalle, 1646). Los registros sedimentarios señalan que los limones y/o naranjos (Rutaceae) fueron uno de los primeros frutales en cultivarse en la cuenca alrededor de 1620 y posteriormente alrededor de 1730 , siguieron los árboles del género Prunus, de los cuales los cerezos son hoy en día los más abundantes. Otra planta que fue muy importante y tempranamente cultivada es la frutilla [Fragaria chiloensis]. Planta nativa que fue domesticada por los indios y rápidamente asimilada por los españoles. Esta era muy común en los territorios de los Partidos de Puchacay, Rere e Itata (Staudt, 1999), y probablemente, fue cultivada dentro de las primeras estancias situadas en el valle del Itata.

\section{Introducción de especies para fines ganaderos}

Además de la agricultura, otra actividad importante que se realizaba intensamente, desde
Cauquenes (Región del Maule) hasta el BioBio, era la ganadería (Cunill, 1971; Gay, 1862; Schneider, 1904). Desde los inicios de la conquista, fueron establecidas grandes estancias, inicialmente cercanas a los fuertes, y posteriormente, a los poblados para abastecer de forraje al ganado español (Villalobos, 1995, 2013). Así, desde 1610 se puede distinguir la presencia y posterior incremento de las Fabaceae. Probablemente en sus inicios fue la alfalfa (M. sativa), y luego se fueron integrando otras especies de esta familia (ver tabla 1). Esta planta es señalada por primera vez para el país en 1847 (Matthei, 1995). No obstante, Gay junto a otros cronistas de la época, indican que la alfalfa fue la planta forrajera más ampliamente utilizada por los españoles durante los s. XVII-XIX (Gay, 1862, 1865; Molina, 1788; Ovalle, 1646). A mediados del siglo XIX, debido a la independencia de Chile y al creciente desarrollo económico cultural, se introducen diversas plantas. Entre las especies forrajeras exóticas de la misma familia de las Fabaceae que fueron introducidas durante este periodo, encontramos a G. officinalis, T. pratense, T. repens y T. dubium. Galega fue introducida a mediados del s. XIX según Schneider (1904) y Matthei (1995) la indica para el año 1881. Las especies de Trifolium mencionadas habrían sido introducidas alrededor de 1870 según Schneider (1904) y son señaladas inicialmente para el país poco tiempo después, en 1930, 1897 y 1897 respectivamente (Matthei, 1995). No obstante, Ovalle nos menciona que durante el s. XVII también se cultivaba el "trébol" para el forraje de los animales, y poco más tarde, Gay lo indica para Concepción, señalando que aparte de la alfalfa, se utilizaba bastante el "trébol francés". Esto indicaría que algunas Fabaceae pudieron haber sido introducidas durante la conquista y haberse establecido en la zona de estudio mucho antes de lo indicado por Matthei (1995), situación que se evidencia en el perfil polínico (Fig. 5).

La introducción accidental de algunas plantas como Plantago y probablemente Rumex se evidencia tempranamente en el perfil polínico; $P$. major y $P$. lanceolata fueron descritas por primera vez para Chile en 1847 y 1860, respectivamente (Matthei, 1995). No obstante, Schneider (1904), señala que para el año 1870 "Plantago" ya presentaba una amplia distribución. $R$. acetosella y R. crispus fueron descritas por primera vez en 1851 
(Matthei, 1995). Sin embargo, existe evidencia paleolimnológica que señala la presencia de este género en la Región de la Araucanía $\left(38^{\circ} 26^{\prime} \mathrm{S}\right.$, $71^{\circ} 19^{\prime} \mathrm{O}$ ) a partir de 1750 (Fletcher \& Moreno, 2012). Región que fue poblada más tardíamente que la Región del Bio-Bio, por lo que estas especies pudieron haberse establecido mucho antes de 1750 (ver tabla 1).

\section{Introducción de especies para fines forestales}

Desde 1850 se puede ver en el perfil polínico que las plantas sembradas para diversos fines (agrícolas o ganaderos), vale decir: Fragaria, Poaceae $>40 \mu \mathrm{m}$, Fabaceae, Rutaceae y más tarde Prunus, comienzan a disminuir. Proceso que podría estar asociado a varios factores: (i) al empobrecimiento de los suelos e incremento de la erosión, situación que señalan varios autores para la época (Albert, 1906; Cunill, 1971; Gay, 1862); (ii) al cambio en el uso de suelo, de agrícola a silvícola (Aguayo et al., 2009; Camus, 2006; Pauchard et al., 2011; Schneider, 1904) y; (iii) a la migración masiva hacia las ciudades, lo que genero el abandono de las tierras, siendo Concepción y Chillán los centros urbanos que más incrementaron su población en esta zona (RuizTagle, 1966). Probablemente estos tres factores actuaron de manera casi conjunta y conllevaron a un abandono paulatino de la agricultura dentro de la cuenca del río Itata. De esta forma, en el registro polínico se puede verificar que los cultivos de cereales comienzan a disminuir drásticamente después de 1840, momento en el cual empiezan a ser reemplazados por Pinus spp (Fig. 4 y 5). Alrededor del año 1850 se identificaron dentro de la cuenca los siguientes árboles forestales: Alnus, Acacia, Cupressus, Eucalyptus, y Pinus, siendo este último el que presenta la información histórica más precisa. Según el registro polínico Pinus, es identificado por primera vez alrededor del año 1850, mientras que la data histórica lo señala para el año 1865 , en la cuenca del Itata. Del resto de las especies encontradas en los sedimentos, Eucalyptus se registró alrededor de 1870 y Cupressus en 1830, mientras que la bibliografía indica que en el año 1881, ya había plantaciones de estas especies en Lota. Siguiendo con el registro, encontramos a Acacia en 1870 y Alnus en 1900. De las cuales no se encontró información acerca de su data de introducción en la región. No obstante, en Chile, A. dealbata se reporta por primera vez en 1869 y A. melanoxylon en 1923 (Fuentes et al., 2014). Para el caso de Alnus glutinosa la bibliografía señala el año 1869 (Fuentes et al., 2014). Este último genero ya estaba incluido dentro del catálogo de semillas, que la Quinta Normal disponía para la venta en 1893 como A. communis.

De las especies forestales mencionadas anteriormente, las plantaciones de pino, son las que actualmente dominan el paisaje natural de la cuenca, en desmedro de las especies agrícolas inicialmente introducidas por los españoles (Fig. 6). Si bien, a mediados del s. XIX se registraron por primera vez dentro del perfil de polen, es alrededor de 1910 cuando se expanden más drásticamente, debido a las iniciativas de replantación forestal propuestas con la finalidad de satisfacer la demanda en madera y detener la erosión causada por la sobreexplotación del suelo agrícola de los siglos anteriores (Albert, 1906; Camus, 2006).

Factores históricos y ambientales que condicionaron la vegetación actual

En el perfil polínico se ve que la abundancia de las Poaceae nativas disminuye a través del tiempo, no obstante, los árboles nativos continúan prevaleciendo sin cambios importantes, pese a la alta representatividad de las especies exóticas. Probablemente, las primeras especies exóticas (frutales, especies agrícolas y ganaderas), se habrían establecido en hábitats de praderas naturales, no alterando mayormente a la flora arbórea nativa. Mientras que las especies forestales, introducidas con posterioridad, habrían ocupado parte de estas praderas naturales, desplazando a las especies cultivables, y además otros hábitats disponibles como "los terrenos arenosos casi inútiles", situados en la cuenca del río Itata como lo señala Schneider (1904).

En el desarrollo de la vegetación de la cuenca del río Itata es posible identificar diferentes factores que influenciaron el establecimiento de las especies exóticas. Entre ellos destaca la baja riqueza de especies nativas, la disponibilidad de hábitat y la rápida capacidad adaptativa de las especies introducidas, características destacadas por varios autores (Figueroa et al., 2004; Ovalle, 1646; Pauchard et al., 2011; Reiche 1934-1937; 


\section{P. Vargas et al. - Rápido movimiento de plantas exóticas en Chile Central}

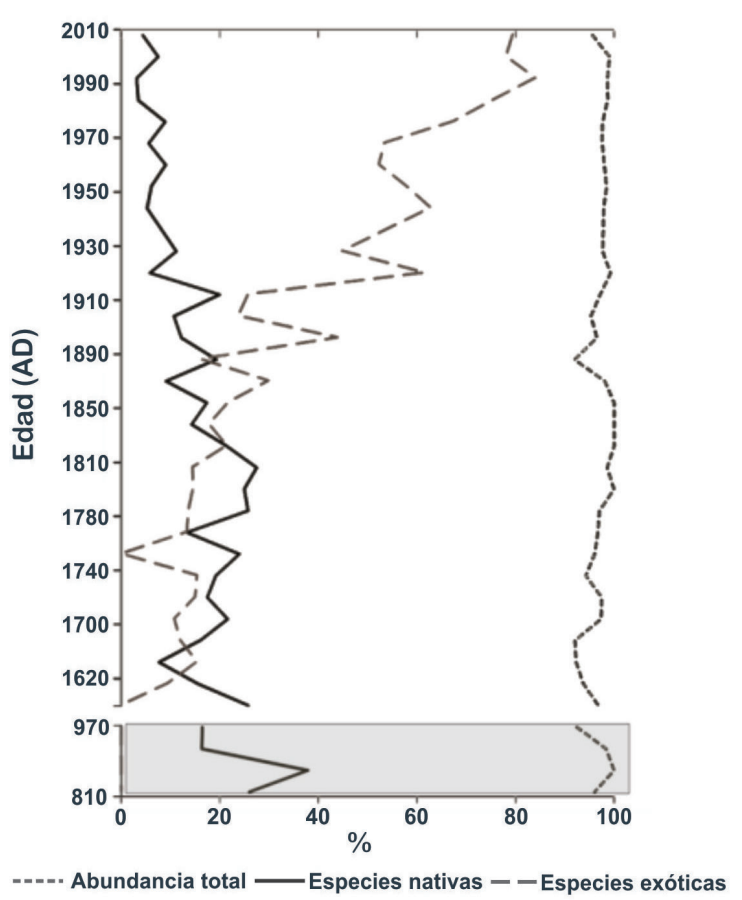

Fig. 6. Grafico de las abundancias relativas de las taxones registrados en el diagrama polínico. En él se señalan las variaciones a través del tiempo de las abundancias de los taxones exóticos y nativos. Además se distingue también la abundancia total y la línea de base para obtener valores de referencia. En éste análisis se excluyen las especies de amplia distribución.

Schneider, 1904; Torrejón \& Cisterna, 2002). Además, también se deben mencionar los factores históricos que favorecieron la introducción y dispersión de estas nuevas especies. Estos factores fueron:

-La introducción de especies realizada por los conquistadores españoles y el trueque que se produjo de manera muy temprana entre mapuches y españoles, en dónde se intercambiaban semillas y animales,

-La introducción masiva de semillas con fines agrícolas y ganaderos y la introducción accidental de otros tipos de semillas, las cuales se aclimataron y expandieron rápidamente por todo el territorio,

-El terremoto de Lima y las pestes que afectaron al Perú (en 1697), eventos que dieron pie a la fiebre del trigo,
-La Guerra de Arauco, y posteriormente, La Guerra de la Independencia que generaron reiterados disturbios, incendios y abandono de tierras propiciando el desarrollo y la dispersión de algunas especies exóticas con alto potencial invasor (e.g. Plantago major y P. lanceolata, el cardo (Cirsium spp), Rumex acetosella y $R$. crispus, M. sativa, Trifolium pratense, T. repens у T. dubium, entre otros) (Fuentes et al., 2014),

-El desarrollo cultural y la asociación con instituciones extranjeras durante el siglo XIX, que conllevo al desarrollo del jardín botánico y la Quinta Normal de Agricultura, quienes introducían y distribuían nuevas especies a todo el territorio nacional,

-La extensión de líneas férreas y caminos hacia el sur conectando a la Región del Bio-Bio con Santiago, facilitando la distribución y dispersión de estas especies,

-Finalmente, la baja productividad agrícola, que se evidenció durante el s. XIX, la erosión de los suelos, el creciente desarrollo urbano y poblacional y la alta demanda de madera, propiciaron la introducción de especies arbóreas forestales.

Tanto los factores, históricos como ambientales, actuaron de manera sinérgica para propiciar la introducción, dispersión y establecimiento de estas nuevas especies en la Región del Bio-Bio. De esta forma, el paisaje actual de la cuenca del río Itata está dominado por $P$. radiata sin embargo, también se pueden encontrar sectores agrícolas con plantaciones de frutales (principalmente de Prunus cerasus, P. aviun y $P$. persica), de vid (Vitis spp) y hortalizas. Así también, de manera general, en las zonas habitadas se distinguen especies ornamentales como Alnus glutinosa, Acacea dealbata y A. melanoxylon, entre otras. En los llanos poco poblados encontramos asociaciones mixtas con especies nativas e introducidas de Acacea caven, L. caustica, Q. saponaria, C. alba, C. spinosissima con Rosa rubiginosa (mosqueta) y Rubus ulmifolius (mora) y diversas especies de Fabaceae y Poaceae. En las quebradas, en sitios aislados y zonas altas de la cuenca prevalecen especies nativas del bosque laurifolio valdiviano. De esta forma, el paisaje que conocieron los primeros cronistas es muy diferente al actual, sin embargo, aún se pueden encontrar algunas de las especies descritas por ellos en el territorio. 


\section{Agradecimientos}

Agradecemos a: Fondecyt No 1120807, Proyecto CRHIAM /CONICYT/FONDAP/15130015; a Becas CONICYT, por financiar mis estudios de postgrado y a Denisse Álvarez por la ayuda prestada tanto en el laboratorio como en el trabajo de campo.

\section{Biblografía}

AGUAYO, M., A. PAUCHARD., G. AZÓCAR, \& O. PARRA. 2009. Cambio del uso de suelo en el centro sur de Chile a fines del siglo XX. Entendidendo la dinámica espacial y temporal del paisaje. Rev. Chil. Hist. Nat. 82: 361-374.

ALBERT, F. 1906. La replantación de los cerros áridos del pais. Imprenta moderna, Santiago de Chile.

ALBERT, F. 1907. Plan general para el cultivo de bosques. Imprenta cervantes, Santiago de Chile.

APPLEBY, P. G. \& F. Oldfield. 1978. The calculation of lead-210 dates assuming a constant rate of supply of unsupported ${ }^{210} \mathrm{~Pb}$ to the sediment. Catena $5: 1-8$.

ARROYO, M., C. MARTICORENA., O. MATTHEI \& L. CAVIERES. 2000. Plant invasions in Chile: Present patterns and future predictions. In Invasive species in a changing world. Haroal A. Mooney and Richard J. Hobbs (eds), pp. 385-421. Washington, United States of America.

ARROYO, M. T. K \& L. A. CAVIERES. 1997. The Mediterranean-type climate flora of central ChileWhat do we know and how can we assure its protection. Noticiero de biología 5: 48-56.

BIBAR, G. 1966. Cronica y relación copiosa y uerdadera de los Reynos de Chile. Tomo II. Edición Facsimilar y a Plana del Fondo histórico y Bibliográfico José Toribio Medina, Santiago de Chile.

BOLÓS, M. 1992. La evolución o arquitectura del paisaje. En: Bolós, M. (ed) Manual de Ciencia del paisaje teoría, métodos y aplicaciones. Masso S.A., Barcelona, España.

BOYD, W. E \& V.A. HALL. 1998. Landmarks on the frontiers of palynology: an introduction to the IX. International Palynological Congress Special Issue on New Frontiers and Applications in Palynology. Rev. Palaeobot. Palynol.103: $1-10$.

CAMUS, P. 2006. Ambiente, Bosques y gestión forestal en Chile 1541-2005. Ed. Dirección de Bibliotecas, Archivos y Museos. LOM. Santiago, Chile.

COWLING, R., P. RUNDEL., B. LAMONT., M.K. ARROYO \& M. ARIANOUTSOU. 1996. Plant diversity in Mediterranean-climate regions. Trends Ecol. 11: $362-366$.
CUNILL, P. 1971. Chile meridional criollo: su geografía humana en 1700. Cuadernos Geográficos del Sur: 21-75.

DIRECCIÓN METEOROLÓGICA DE CHILE. 2011. ANUARIO CLIMATOLOGICO 2010, SANTIAGO - CHILE 2011. Disponible en: http://164.77.222.61/ climatologia/ [Acceso:12-12-2015].

DONOSO, C \& A. LARA. 1996. Utilización de los bosques nativos en Chile: pasado, presente y futuro. En: ARMESTO, J. J., C. VILLAGRÁN \& M.K. ARROYO. (eds) Ecología de los bosques nativos de Chile. Editorial Universitaria, Santiago, Chile.

ERDTMAN, G. 1960. The acetolysis method. Svensk Botanisk Tidskrift. 54: 561-564.

FIGUEROA, J., S. CASTRO., P. MARQUET \& F. JAKSIC. 2004. Exotic plant invasion to the mediterranean region of Chile: Causes, history and impacts. Rev. Chil. Hist. Nat. 77: 465-483.

FIGUEROA, J. A., S. TEILLIER \& S.A. CASTRO. 2011. Diversity patterns and composition of native and exotic floras in central Chile. Acta Oecol. 37: $103-109$.

FLETCHER, M. S \& P.I. MORENO. 2012. Vegetation, climate and fire regime changes in the Andean region of southern Chile $\left(38^{\circ} \mathrm{S}\right)$ covaried with centennialscale climate anomalies in the tropical Pacific over the last 1500 years. Quat. Sci. Rev. 46: 46-56.

FOSTER, D. R., P.K. SCHOONMAKER \& S.T.A. PICKETT. 1990. Insights from Paleoecology to Community Ecology. Tree. 5: 119 - 121.

FRÊNE, C \& A. NÚÑEZ. 2010. Hacia un nuevo modelo forestal en Chile. Revista Bosque Nativo. 47: 25-35.

FUENTES, N., P. SÁNCHEZ., A. PAUCHARD., J. URRUTIA., L. CAVIERES, L \& A. MARTICORENA. 2014. Plantas invasoras del centro-sur de Chile: Una guía de campo. Laboratorio de Invasiones Biológicas (LIB), Concepción, Chile.

GAY, C. 1862. Historia fisica y politica de Chile. Agricultura. Tomo primero. Museo de historia natural, Santiago de Chile.

GAJARDO, R. 1994. La vegetación natural de Chile, clasificación y distribución geográfica. $1^{\text {era }}$ Edición, Ed. Universitaria, Santiago de Chile, Chile.

GAY, C. 1865. Historia fisica y política de Chile. Agricultura. Tomo segundo. Museo de historia natural, Santiago de Chile.

GRIMM, E. 1987. Coniss: A Fortran 77 program for stratigraphically constrained cluster analysis by the method of incremental sum of squares. Computers and Geosciences. 13: 13-35.

GRIMM, E. 1991. Tilia and Tilia graph. Springfield: Illinois State Museum.

GUARDA, G. 1968. La ciudad chilena del siglo XVIII. Centro editor de América Latina S.A. Buenos Aires, Argentina. 


\section{P. Vargas et al. - Rápido movimiento de plantas exóticas en Chile Central}

GUARDA, G. 1990. Flandes indiano: las fortificaciones del reino de Chile (1541-1826). Ediciones de la Universidad Católica de Chile, Santiago, Chile.

HERNÁNDEZ, A., MIRANDA, M. D., ARELLANO, E. C. Y DOBBS, C. 2016. Landscape trajectories and their effect on fragmentation for a Mediterranean semi-arid ecosystem in Central Chile. J. Arid Environ. $127: 74-81$.

HEUSSER, C. 1971. Pollen and spores of Chile. Modern types of the Pteridophytas, Gimnospermae and Angiospermae. University of Arizona.

HOBBIE, J. E., S.R. CARPENTER., N.B. GRIMM., J.R. GOSZ \& T.R. SEASTEDT. 2003. The US long term ecological research program. BioScience. 53: 21-32.

INE. 2007. Enfoque estadístico. VII Censo agropecuario y forestal. Disponible en: http://www.ine.cl/canales/ sala_prensa/noticias $/ 2007 / \mathrm{marzo} /$ files/septimo_ censo_agroagropecu_pdf.pdf. [Acceso: 03-062013].

INE. 2013. Población, país y regiones: Actualización población 2002-2012 y proyecciones 2013-2020. Disponible en: http://www.ine.cl/canales/chile_ estadistico/familias/demograficas_vitales.php [Acceso: 15-12- 2015].

JIMÉNEZ, A., A. PAUCHARD., L. CAVIERES., A. MARTICORENA \& R. BUSTAMANTE 2008. Do climatically similar regions contain simlar alien floras? A comparison between the mediterranean areas of central Chile and California. J. Biogeogr. 35: 614-624.

LISITSYNA, O. V., T. GIESECKE \& S. HICKS. 2011. Exploring pollen percentage threshold values as an indication for the regional presence of major European tres. Rev. Palaeobot. Palynol. 166: 311 -324 .

LUEBERT, F \& P. PLISCOFF. 2006. Sinopsis bioclimática y vegetacional de Chile. Editorial Universitaria, Santiago de Chile.

MACKENNA, V. 1867. La cosecha de trigo en Chile. Circular.

MACKENNA, V. 1881. La edad de oro. Imprenta cervantes, Santiago.

MARTICORENA, C \& R. RODRIGUEZ. 1995. Flora de Chile I: Pteridophyta-Gymnospermae. Universidad de Concepción, Concepción.

MATTHEI, O. 1995. Manual de las malezas que crecen en Chile. Alfabeta Impresores. Santiago de Chile.

MCCORMAC, F., A. HOGG., P. BLACKWELL., C. BICK., T. HIGHAM \& P. REIMER. 2004. SHCal04 Southern Hemisphere Calibration 0-11 cal Kyr BP. Radiocarbon 46: 1087-1092.

MILLER, A. 1976. The climate of Chile. In Schwerdtfeger $\mathrm{W}$, editor. World survey of climatology. Elsevier, 107-34.
MOLINA, A. 1788. Compendio de la historia civil del Reyno de Chile. Parte segunda. Imprenta de Sacha, Madrid.

MOLINA, A. 1795. Compendio de la historia civil del Reyno de Chile. Parte Segunda. Imprenta de Sacha. Madrid.

MUNSELL COLORS. 2009. Soil-Colors-Charts with genuine Munsell colors chips.

NIETO-LUGILDE, D., K.C. MAGUIRE., J.L. BLOIS., J.W. WILLIAMS \& M.C. FITZPATRICK. 2015. Close agreement between pollen-based and forest inventory-based models of vegetation turnover. Glob. Ecol. Biogeogr. 24: 905 - 916.

ODGAARD, V. B. 2013. Pollen Methods and Studies | Reconstructing Past Biodiversity Development. Earth Sistems and Environmental Science Encyclopedia of Quaternary Science (Second Edition). Pages 816 - 820 .

ORELLANA, M. 1992. Historia y antropología de la isla de La Laja. Editorial Universitaria. Santiago de Chile.

OTERO, L. 2006. La huella del fuego. Historia de los bosques nativos, poblamientos y cambios en el paisaje en el sur de Chile. Editorial Pehuen editores, Santiago, Chile.

OVALLE, A. 1646. Historica relación del Reyno de Chile. Roma.

PAUCHARD, A., M. AGUAYO., E. PEÑA \& R. URRUTIA. 2006. Multiple effects of urbanization on the biodiversity of developing countries: The case of a fast-growing metropolitan area (Concepción, Chile). Biol. Conserv. 127: 272-281.

PAUCHARD, A., R. GARCÍA., B. LANGDON \& N. FUENTES. 2011. Invasiones de plantas introducidas en Chile y su impacto en la biodiversidad: Historia, estado actual y desafíos para su gestión (2-43). In Successful and failed experiences in biodiversity conservation: Lessons and policy recomendations from the American Continent. Eugenio Figueroa Ed. Santiago, Chile.

PÖEPPIG, E. 1960. Un testigo de la alborada de Chile (1826-1829). Editora Zigzag. Santiago de Chile.

QUINTA NORMAL DE AGRICULTURA. 1893. Catálogo. Imprenta cervantes, Santiago de Chile.

REICHE, K. 1934-1937. Geografía botánica de Chile. Traducción del alemán de Gualterio Looser. Tomo II, Ed. Impr. Universitaria, Santiago, Chile.

RUIZ-TAGLE, C. 1966. Concentración de la población y desarrollo económico -El caso chileno. Santiago de Chile.

SALA, O. E., F.C. STUART., J.J. ARMESTO., E. BERLOW., J. BLOOMPELD., R. DIRZO., E. HUBER-SANWALD., L.F. HUENNEKE., R.B. JACKSON., A. KINZIG., R. LEEMANS., D.M. LODGE., H.A. MOONEY., M. OESTERHELD., 
Bol. Soc. Argent. Bot. 52 (1) 2017

M.L. POFF., M.T. SYKES., D.H. WALKER., M. WALKER \& D.H. WALL. 2000. Global Biodiversity Scenarios for the Year 2100. S C I E N C E' C O M P A S S 287: 1770 - 1774 .

SCHNEIDER, T. 1904. La Agricultura en Chile en los últimos ciento cincuenta años. Imprenta Litografía $\mathrm{i}$ encuadernación Barcelona, Santiago de Chile.

STAUDT, G. 1999. Systematics and Geographic Distribution of the American Strawberry Species: Taxonomic Studies in the Genus Fragaria (Rosaceae: Potentilleae). University of California Press.

SZABÓ, P. 2010. Why history matters in ecology: an interdisciplinary perspective. Environ. Conserv. 37: $380-387$.
TORREJÓN, F. \& M. CISTERNAS. 2002. Alteraciones del paisaje ecológico araucano por la asimilación mapuche de la agroganadería hispano-mediterránea (siglos XVI y XVII). Rev. Chil. Hist. Nat. 75: 729736.

VILLALOBOS, S. 1995. Vida fronteriza en la Araucanía, el mito de la guerra de Arauco. Editorial Andrés Bello, Santiago, Chile.

VILLALOBOS, S. 2013. Breve historia de Chile. Editorial Universitaria, Santiago de Chile.

Recibido el 2 de junio de 2016, aceptado el 21 de octubre de 2016 . 